\title{
CORTOCIRCUITOS (O LA HISTORIA DE UNA NEGACIÓN CRÍTICA): LOS OJOS DE BAMBÚ, DE MERCEDES VALDIVIESO
}

\author{
Lorena Amaro \\ Pontificia Universidad Católica de Chile \\ Santiago, Chile \\ lamaro@uc.cl
}

RESUMEN / ABSTRACT

La tradición crítica ha construido complejos vínculos con las figuras de escritoras a lo largo del siglo XX en Chile, tema que ha sido abordado con diversos matices a través de ejemplos como los de Mistral, Bombal o Brunet, autoras valoradas dentro del canon, pero a costa de operaciones que buscaban "masculinizar" su trabajo, o bien, reducirlo a sus aspectos más inocuos y convencionalmente "femeninos", en un doble movimiento de aceptación y rechazo que se sigue repitiendo hoy en diversos espacios culturales. Por otra parte, la inscripción de apenas un puñado "excepcional" de escritoras en el campo, "cortocircuita", como escribió la escritora catalana Maria-Mercè Marçal (cit. en Pérez y Torras 14), los espacios de intersubjetividad femenina. El régimen de excepcionalidad de estas autorías lleva a que en las historias literarias solo algunas brillen y tantas otras sean olvidadas. La excepcionalidad también opera en los corpus literarios: por lo general la crítica destaca una o dos obras de las escritoras de antaño y el resto permanece invisibilizado, algo que no ocurre cuando se trata del canon masculino. Ilustro este proceso en el siguiente artículo, rescatando para el análisis la tercera novela de Mercedes Valdivieso Los ojos de bambú (1964). A diferencia de otros textos suyos, este relato no tuvo una buena recepción crítica, probablemente porque la autora aborda aquí un tema muy poco "femenino" para los críticos que la leyeron entonces: la Revolución comunista china en el contexto de la Guerra Fría.

PalabRas ClaVE: historia literaria chilena, feminismo, canon, misoginia, Mercedes Valdivieso.

\section{SHORT CIRCUITS (OR THE HISTORY OF A CRITICAL DENIAL): LOS OJOS DE BAMBÚ, BY MERCEDES VALDIVIESO}

In Chile, critical tradition has built complex connections with female writers throughout the Twentieth Century. This topic has been addressed in its different nuances through texts of 
canonical female writers such as Mistral, Bombal, and Brunet. However, their texts were either devoid of their masculinizing operatives or reduced to their more harmless and conventional feminine aspects. This simultaneous movement of acceptance and rejection perpetuates today in different cultural spaces. Additionally, the fact that only a handful of 'exceptional'female writers inscribe in the literary field, 'short circuits' the spaces of feminine intersubjectivity, in words of the Catalan writer Maria-Mercè Marçal (in Torras y Pérez). The exceptional character of these authorships prompts some to shine while others are forgotten. Furthermore, exceptionality operates in various literary corpora: criticism frequently highlights one or two literary works from past writers. The rest remains invisible, contrary to the situation of the masculine canon. In the following article, I illustrate this process by salvaging the third novel written by Mercedes Valdivieso, Los Ojos de Bambú (1964), for analysis. Unlike other texts written by the author, it was not well-received by literary critics of the time, probably because the author refers to an untypical topic for women: the Chinese Communist Revolution in the context of the Cold War.

KEYWORDS: Chilean literary history, feminism, canon, misogyny, Mercedes Valdivieso.

Recepción: 01/07/2021

Aprobación: 15/09/2021

Cuánta paciencia y temple debieron tener Mercedes Valdivieso y otras escritoras de la generación del 50 para enfrentar a la prensa y la crítica de su tiempo. El mismo año que se publicaba La brecha (1961), acontecimiento que este dossier celebra por la sacudida que desató la novela en el ambiente literario y cultural chileno, aparecía una entrevista anónima en revista Ercilla que, bajo el título "Autora de La Brecha: No soy la protagonista", deja entrever varios de los prejuicios con que les lectores de la época recibieron el texto. Aunque la protagonista carecía de un nombre, le preguntaban a su creadora si se trataba de un relato autobiográfico y parecían atribuir con ello su éxito -la primera edición se agotó rápidamente y hubo cinco el mismo año en que apareció-al morbo que podía producir, en la sociedad de la época, una historia de divorcio. La entrevista insiste bastante en esto (y nada en la literatura): le preguntan a Mercedes Valdivieso, por ejemplo, si se considera "gloriófila"; renglones más abajo, cómo definiría ella el éxito y qué "peligros" puede traer aparejados. El texto parece responder por sí solo a estas preguntas cuando se destaca, en un recuadro, que la obra fue escrita "en tiempo record" y los editores la leyeron y aprobaron, también, en "tiempo relámpago". ¿Tan buena acogida de un texto primerizo, y tan rápido? ¿A qué podía deberse? Desde luego que el reportaje no parece inclinarse por el talento de las escritoras, cuando sin reparo alguno le hacen a Valdivieso una pregunta que hoy nos parece ofensiva, absolutamente inverosímil: “¿Cree usted que existen las mujeres 
inteligentes? ¿Podría nombrar tres?”, a lo que ella responde asertivamente con otra pregunta: “¿Cree posible negarlo? ¿Solo tres?”.

\section{EL CORTOCIRCUITO DE LA CRÍTICA}

Mal que les pesara a periodistas, críticos y académicos misóginos de aquel tiempo, la novela de Valdivieso habría de tener larga vida; numerosos análisis dan cuenta, en las décadas posteriores, de cómo abordó un mundo restrictivo para las mujeres, en una novela de "actitud contestataria" (Euler 344) respecto de la producción de la norma de género en el Chile de los años sesenta. Se instaló así en el panorama y en la historia literaria nacional como un hito, que marca en gran medida un antes y un después, como lo hicieron también, en su tiempo, Montaña adentro, de Brunet (1923) o La última niebla (1934), de Bombal. No habrían de correr idéntica suerte otros libros posteriores: $L a$ tierra que les di (1963), Los ojos de bambú (1964) y Las noches y un día (1971), textos que fueron recibidos con menor entusiasmo. La publicación de la que sería su última novela, poco antes de su muerte, Maldita yo entre las mujeres (1991), despertó nuevamente el interés por su obra. Allí reescribía la leyenda de La Quintrala, mujer colonial demonizada por los historiadores.

¿Qué ocurrió con la recepción crítica de esas otras ficciones de la autora, aquellas que no tuvieron el mismo éxito? Al respecto, es necesario considerar que la tradición crítica patriarcal ha construido complejos vínculos con las figuras de escritoras a lo largo del siglo XX en Chile, tema que ha sido abordado y ejemplificado en sus numerosos matices a través de las trayectorias de Gabriela Mistral, María Luisa Bombal o Marta Brunet. Su valorización se acompañó de una singular inclusión en el canon, que buscaba "masculinizar" el talento de estas autoras, al tiempo que reducía su lectura a los aspectos que consideraban más inocuos y convencionalmente "femeninos". Se produce así un doble movimiento de aceptación y rechazo; a través del aplauso de un puñado de escritoras más destacadas se "cortocircuitan" los espacios de intersubjetividad femenina (Marçal cit. en Pérez y Torras 14) y se proponen historias literarias en que solo "algunas" brillan y muchas otras son olvidadas, en un régimen de excepcionalidad que no aplica del mismo modo a los escritores. Mecanismos como este son descritos con detalle por Joanna Russ en el ya clásico ensayo Cómo acabar con la escritura de las mujeres, de 1983, en el que la autora describe, basándose sobre todo en ejemplos de literatura en lengua inglesa, diversos mecanismos de invisibilización; bajo 
los acápites "Aislamiento" y "Anomalía" describe lo que llama el "mito del logro aislado" (112 y ss.); por el que se pretende que una autora tiene solo una obra significativa, lo que deja en sombras el resto de su trabajo, o las ideas de rareza y excentricidad que justificarían la inclusión atomizada de algunas mujeres en antologías e historias literarias, con el consecuente cortocircuito crítico que impide proyectar la autoría femenina de manera más integral, desde una mirada histórica, estética e ideológica y a la vez diacrónica y sincrónica. La teórica y crítica francesa Christine Planté también analiza las formas en que se legitiman y excluyen las prácticas artísticas y literarias de las mujeres a partir de la moderna noción de excepcionalidad, que, en el caso de la obras realizadas por varones, se vincula con lo genial, extraordinario y singular, pero en el caso de las mujeres colinda más bien con la "rareza", concepto que devalúa la excepcionalidad misma y, con ello, la producción femenina en general. Aina Pérez y Meri Torras plantean la misma crítica con estas palabras: la excepcionalidad "confirma las limitaciones del 'sexo femenino"" (15).

Este tipo de operaciones impide la elaboración de un tramado histórico realmente inclusivo de la escritura de mujeres. El cortocircuito afecta la lectura analítica de estas obras ya que se las suele leer separadas de sus contextos de producción, como una suerte de acápite de la literatura de su tiempo (la literatura "universal" o gran literatura, escrita por hombres). Tales exclusiones se proyectan, consecuentemente, en la recepción parcial de tan solo algunos textos de autoría femenina, en desmedro de otros que quedan en la sombra, inubicables en los anaqueles de bibliotecas y librerías. Se trata de una marginalidad injusta, como si las escritoras fueran autoras de un único libro que valiera la pena leer. Este marco conceptual permite comprender por qué la tercera novela de Mercedes Valdivieso, Los ojos de bambú, publicada por Zig-Zag, tuvo tan solo una reedición en $1965^{1} \mathrm{y}$ también ayuda a entender la inexplicable recepción particularmente fría que le dio la crítica literaria.

\footnotetext{
Recién cincuenta años después, en 2021, ha vuelto a ser publicada, esta vez por Ediciones Universidad Alberto Hurtado y con un prólogo de Lucía Guerra, en el contexto de la colección "Biblioteca recobrada", que rescata el trabajo de narradoras chilenas de los siglos XIX y XX.
} 


\section{LA INTRUSA}

La novela es precedida por un prólogo de la autora, quien refiere su propia experiencia durante una estadía de diez meses en China, y presenta la historia de Clara, pintora, en un viaje a ese país durante los años previos a la Revolución Cultural y en el momento de mayor tensión durante la Guerra Fría: la llamada "crisis de los misiles" y el bloqueo de Estados Unidos a Cuba (1962), hecho referido en el libro. Consta de trece segmentos largos, narrados en tercera persona, y tres fragmentos de la correspondencia entre Clara y Javier, su marido, quien se encuentra en Chile, próximo a reunirse con ella. A esto se suman una breve cronología histórica china y el prólogo antes mencionado, en el que Valdivieso confiesa que "escribir este libro no me resultó fácil" (9). Tanto esta introducción, como la presencia protagónica en el relato de una artista proveniente de una familia de élite (un mundo que Valdivieso conoce directamente y explora en sus demás trabajos), permiten leer en espejo la novela y ver en ella una puesta en abismo de su enunciación; como lo plantea Lucía Guerra, "Los ojos de bambú tiene una fuerte relación con la trama biográfica de la autora, razón por la cual posee importantes rasgos testimoniales" (9): así como Clara intenta mostrar la China del presente a través de su trabajo pictórico -intento que no sabemos si tendrá éxito o no finalmente-, Mercedes Valdivieso nos ofrece una reflexión literaria sobre este importante proceso histórico, desde la perspectiva de una mujer culta y sensible que procura penetrar en el conflictivo tramado artístico y político de su contemporaneidad.

El libro, no obstante, fue adversamente recibido por la crítica. En el capítulo correspondiente a Mercedes Valdivieso, de Escritoras chilenas (compilado por Patricia Rubio), Mariechen Euler da cuenta de ello. Ricardo Latcham describe la novela como "un cuadro honesto de realidad a menudo deformada" (cit. en Euler 348); a Alone parece no gustarle una atmósfera que "se ve sacudida y, al fin deshecha por los disparos políticos, que no se sabe si creer o no creer" (ibid.); Gustavo Labarca Garat desconfía de que esta sea realmente una novela y Hernán Loyola echa de menos "documentación sobre el tema" que ella aborda, lo que la hace "trastabillar": "No es sólo una obra ambiciosa (lo que es legítimo) sino que carece de humildad (que no es lo mismo)" (cit. en Euler 348). A estos comentarios sumo otro, de Fernando Durán Díaz, recogido de Memoria chilena, donde este crítico plantea que el texto constituye un "retroceso" de la autora: 
Poca o casi nada de creación novelesca encontramos en el correr de sus páginas. Antes que novela semeja ser una crónica a la que se ha disfrazado con ropaje novelesco. Sus personajes tienen poca vida, escasa consistencia humana. El conflicto ideológico que impera en el libro, la acumulación de diálogos políticos, culturales, etcétera, hace que los seres que conforman su mundo adquieran a los ojos del lector, contornos borrosos... (párr. 3).

Entre estas voces críticas, la única que parece positiva es la de otra escritora, Magdalena Petit, quien reivindica la belleza del texto y la manera en que este confronta "el pasado reciente y el salto al futuro" (cit. en Euler 348) de la sociedad china.

Curiosamente, la propia Mariechen Euler, quien busca con su texto realzar el trabajo de Valdivieso, desliza en 1999 algunas nociones estereotipantes, que se pueden revisar a la luz de los feminismos actuales:

Uno de los aciertos del libro es la visión íntima de la voz narrativa que no intenta exponer desde su punto de vista ideológico, sino que lo hace a través de la intuición. El desarraigo de la protagonista y el escepticismo de otros personajes van delineando un cuestionamiento de realidades que están más cerca de la afectividad que del pensamiento lógico (Euler 348).

Con esta aproximación, Euler interpreta los conflictos de la protagonista de la novela -quien sufre un verdadero colapso creativo y existencial a partir del encuentro con los mundos de la China del pasado y la de la revolución, pero también a causa de su propia introspección-desde una idea de lo afectivo/intuitivo, dejando a un lado los numerosos argumentos ideológicos, racionales, expuestos en la novela. Esto minoriza, a su modo -hace veinte años no se escudriñaba como hoy el ámbito de los afectos-, la crítica política que hace el texto y estereotipa la vinculación de las mujeres con la política. Se reproducen aquí los binarismos racionalidad/intuición y espacio público/ espacio privado, que acompañaron el discurso sobre las mujeres al menos en los dos primeros tercios del siglo XX.

Pero no es en vano que desde Alone a Hernán Loyola -dos críticos situados en lugares muy distintos del espectro político, el primero liberal y el segundo comunista-se produzca un evidente cortocircuito ante la novela. Este rechazo parece una reacción, desde quienes detentan poder en el campo, frente a lo que se concibe como una intrusión, la que hace una escritora en temas 
políticos, tradicionalmente dominados por hombres. Leídos en su conjunto, los comentarios críticos recogidos dan a entender, en todos los casos, que la narración de Valdivieso no consigue hablar de "algo", "algo" que le falta al relato y que incluso lo pone en entredicho, lo niega. Es por esto que no lo consideran una novela (¿demasiado "autobiográfica?); plantean que está mal documentada (¿demasiado novelesca?), que es "carente de humildad" o que se encuentra "deshecha" por "disparos políticos" (carente de coherencia).

Probablemente fuera el asunto de la novela -la crítica de una artista e intelectual no solo a la Revolución comunista china, sino también a la oligarquía conservadora chilena, con numerosas reflexiones sobre las relaciones internacionales, la Guerra Fría, la misión social de los artistas y el sentido último de la cultura- el que repercutió tan fuertemente en esta especie de desconcierto crítico de sus contemporáneos, a quienes se les hizo tan atípica (novela defectuosa, crónica disfrazada, autobiografía). Mientras las dos publicaciones anteriores de Valdivieso -La brecha y La tierra que les $d i$ - presentaban a protagonistas femeninas que vivían dilemas seguramente más "legibles" o apropiados, esperables de una mujer -como el proceso de una mujer separada que va conquistando su autonomía o la decadencia del latifundio y la transformación de los valores tradicionales de una familia de la oligarquía, al morir la generación de los abuelos-, Los ojos de bambú comparte con la novela Las noches y un día (1971) -ni siquiera mencionada por Euler en su recuento de Valdivieso- lo que debió ser una inesperada incursión en temas políticos. José Alberto de la Fuente observa esta coincidencia de dos novelas que se arriesgan a la leer la contingencia política de su tiempo:

Los ojos de bambú casi no tuvo crítica en el medio nacional chileno. Algo parecido sucedió con la novela Las noches y un día, cuyo tema es la historia de una pareja de amantes con el fondo electoral de la derrota de Allende en 1964. Si bien la óptica del narrador estaba orientada a la situación social y política, al parecer no se indagó más en el debate que se agudizaba en esos años (5).

\section{CORTOCIRCUITOS POLÍTICOS Y ARTÍSTICOS}

La recepción crítica favorable al trabajo de Valdivieso retorna con la novela Maldita yo entre las mujeres, de tema histórico y con una protagonista excepcional, La Quintrala, uno de los personajes coloniales con más 
representaciones en la historia, la literatura e incluso la televisión chilena. Esto parece confirmar un patrón en la recepción crítica, que acepta de buen grado ciertos temas y retóricas, en tanto rechaza otros. Si bien en todos sus textos Valdivieso se revela como una autora que tuvo plena conciencia de los debates epocales - no solo los que referían a la desigualdad que afectaba a las mujeres-, el reconocimiento crítico viene solo cuando se circunscribe a las reivindicaciones de carácter feminista, pero no cuando se ocupa de la política o las contingencias del espacio público en que ella claramente habitó.

Clara se construye como un personaje liminar, fronterizo. No solo es una mujer de clase alta que ha trasgredido las leyes de la casta al convertirse en artista y unirse a un hombre sin ambiciones económicas: como habitante de un hotel ${ }^{2}$ de habitaciones y rutinas estandarizadas y occidentalizadas, Clara intenta "cruzar" a la otra orilla de una experiencia que le está vetada, así como antes "cruzó" la brecha que separaba su vida familiar de la que realmente deseaba vivir: la de una artista. Como tal, se ha desplazado políticamente y se ha alejado de las convicciones conservadoras familiares, pero una vez más se encuentra en una encrucijada, ya que tampoco adopta una posición revolucionaria ortodoxa, sino que, por el contrario, critica "desde dentro" el proceso chino, un gesto que para Germán -amigo militante de orígenes humildes, como subraya el relato- es consecuencia de su educación y posición privilegiada.

Posiblemente, el rechazo de los críticos se deba a esta arista política. Como el personaje de Germán en la ficción, sus detractores reales tal vez consideraron que no le correspondía a Valdivieso, una mujer de clase alta, involucrarse en política y juzgar sobre un asunto político como la revolución.

\footnotetext{
En su novela lo llama "Hotel Internacional", pero traspone su propia experiencia como alojada en el peculiar Hotel de la Amistad, que entre los años sesenta y ochenta albergó a una enorme cantidad de extranjeros vinculados con el Partido Comunista, viajeros que llegaban a China para trabajar en el marco de la revolución. A ellos no les estaba permitido tener residencias propias en la ciudad. Esta experiencia de Valdivieso ha sido retratada también por otros artistas y escritores, como en la reciente Volver la vista atrás (2020), de Juan Gabriel Vásquez, que recoge aspectos de la estadía del director de cine Sergio Cabrera con su familia en ese lugar, cuando era aún un niño, en los sesenta, y que dejó inconcluso un proyecto fílmico sobre esta historia. Algo similar ocurre con el argentino Pablo Doudchitzky, autor del documental Hotel de la amistad (2015), donde refiere su experiencia entre 1963 y 1967, también con su familia. Resulta muy interesante que Mercedes Valdivieso haya plasmado en su novela, ya en los mismos sesenta, la inquietud que produjo en ella esta singular experiencia de segregación y vigilancia, durante los tensos años que antecedieron a la Revolución Cultural.
} 
No está de más recordar que ella y su esposo, el escritor y académico Jaime Valdivieso, fueron invitados por el gobierno chino en su calidad de amigos del país, para que conocieran de primera mano, como muches otres intelectuales de ese tiempo, el proceso revolucionario. La reacción crítica frente a la novela revela la misoginia con que debieron lidiar las autoras de la generación del 50, retratada por Kottow y Traverso:

La categoría "mujer" en el ámbito letrado designaba no solo a una intrusa, sino a una impostora, que fingía saber. Así, las primeras autoras que escribieron desde la afirmación de su género, principalmente durante el período de efervescencia de los movimientos feministas en América Latina, fueron tachadas de "marisabidillas", "bas-bleu", "bluestocking", "sabelotodo", términos que delataban una impostura en el querer escribir y no tener las capacidades (20).

Desde esta perspectiva, es posible retomar y comprender lo que escribe Hernán Loyola, militante comunista que pocos años más tarde partiría al exilio por causa de la dictadura: la novela, escrita por una mujer burguesa, le resultaba no solo "ambiciosa", sino también carente "de humildad" (cit. en Euler 348). La mirada de Loyola no es muy distinta a la de algunos de los varones que rodean a la protagonista de la ficción de Valdivieso, y como ellos, procura poner a la autora "en su lugar": su provocación, en suma, ha hecho "trastabillar" la ficción, idea que él instala para "desautorizar" a la autora.

Algo similar es lo que vive su protagonista. Clara viene de una familia de élite y ha debido construirse desde la disidencia que implica ser una artista con ideas propias, en un entorno fuertemente patriarcal. Para la familia es una oveja descarriada y, para sus pares intelectuales y artistas, una mujer de clase social alta, dudosamente comprometida con la revolución popular. Es por esto que todos, incluso aquellos hombres que, como Germán, la estiman como artista, buscan "corregirla" políticamente. Solo Javier, el marido, parece no juzgarla, pero se encuentra ausente.

Radicada por unos meses en Pekín, Clara prepara las pinturas con que sus anfitriones esperan dé cuenta del proceso revolucionario, pero enfrenta una tensión cada vez mayor entre ella y su entorno: si bien admira diversos aspectos de la cultura china, tanto de su pasado como de la revolución, tiene dudas sobre aquello que le resulta engañoso y restrictivo de su experiencia como visitante. Ella está sola en el hotel (debe llegar también su marido, quien dictará clases sobre cultura latinoamericana en la universidad) y es reticente 
a vincularse con ese entorno. Anhela adentrarse más en la cotidianidad china. Sin otra salida, conocerá a algunos de los cincuenta invitados hospedados con ella, entre quienes hay un grupo de latinoamericanos. Durante su estadía se irá acercando a los personajes que se revelan más críticos de la experiencia china (los españoles Marta y Vicente y la joven Fanny), distanciándose de quienes encarnan la ortodoxia, principalmente de su amigo chileno, Germán, quien ha sido el gestor de su viaje. Tanto Germán como el joven traductor chino Wang Te-en y el subdirector de Bellas Artes que supervisa su visita, están por completo comprometidos con la causa revolucionaria. La creciente indignación de Clara, así como su necesidad de expresarse y circular con libertad por la ciudad, son molestas para ese entorno masculino que la trata condescendientemente.

En la novela es muy importante la relación con Germán, un antiguo amigo de su esposo. Con ideas de cuño humanista y apelando a la universalidad de los afectos, Clara levanta una mirada crítica al proceso que está presenciando. Sin replegarse a la derecha, sostiene una suerte de socialdemocracia que se resiste a la postura mucho más radical, ortodoxa, de su amigo Germán. Mientras en Chile fue posible su amistad, en China las posiciones se exacerban, alentadas, además, por la diferencia social que hay entre ambos. Germán proviene de una familia campesina humilde, en tanto ella es parte de un grupo terrateniente. Aunque no lo verbaliza, Clara recrimina en Germán su resentimiento (la novela, finalmente, está focalizada en ella, y no en su amigo). Y él, a su vez, la ve como una mujer de clase alta inconsciente de sus privilegios e incluso más que eso: pese a que ella ha renunciado a sus regalías familiares para irse a vivir con Javier, Germán no ve en ello rebeldía: “Es la valentía de quienes han vivido siempre hartos" (Valdivieso 94).

El futuro de China es, entonces, para Germán, una apertura: no ha dejado nada atrás, en Chile, y pisa tierra firme en la revolución. Clara, en cambio, es más cauta y dubitativa. Desde la posición de un humanismo universalista, advierte sobre la amenaza de "perderse" en un laberinto histórico que acabe por borrar las diferencias de los individuos. La expresión de estos temores se halla en la metáfora del hotel, que aparece ya en las primeras páginas de la novela:

Contempla estos pasillos, Germán. Por aquí entré a mi llegada, y recuerdo que cuando quise después bajar al jardín, me perdí en ellos. Como tú, como todos en un principio. Había un reloj a la vuelta, por ese reloj pensé guiarme, pero había otro reloj igual en el extremo 
opuesto y siempre los confundía. Me paraba frente a mi puerta y su número era distinto. ¿Dónde estaba el mío? Corría de nuevo sobre la alfombra, hasta que un empleado me tocaba el hombro pronunciando apenas "Other side". Aún ahora salgo con miedo, temores inexplicables, temor de no llegar nunca a esa esquina, de que la alfombra no termine y se alargue, de volverme a perder en estos pasillos (Valdivieso 20).

Mientras Germán confía en un proceso alimentado por la comunidad disciplinada que surge de la revolución, Clara prefiere mirar hacia el pasado ancestral de ese pueblo para destacar allí expresiones brillantes no del quehacer colectivo, sino de sus individuos. Son varias las ocasiones a lo largo de la novela en que se contraponen estas miradas, principalmente a través de las conversaciones entre estos antiguos amigos:

-Entre nosotros existe una gran diferencia. Tú hablas del hombre y yo hablo del pueblo. Ya se irá de lo general a lo particular. Hacerlo a la inversa es hoy un juego de intelectuales, e intelectuales burgueses, por supuesto. Me molestan tus palabras, son las mismas tan empleadas por el enemigo, sólo te falta hablar de humanismo y libertad. Y estamos en pleno centro de Pekín...

-¡Oh Germán! ¿Por qué colocar en oposición lo individual y lo colectivo? El hombre nunca responderá bien a la colectividad si no tiene profunda conciencia de sí mismo. A esa conciencia tiene tanto derecho el pueblo como lo tiene a bienestar y justicia (Valdivieso 91).

Estas diferencias provocan también disensos estéticos, muy importantes en la instalación de los proyectos revolucionarios del siglo XX. La mirada humanista de Clara parece haberse plasmado en su pintura, que Germán y sus anfitriones reprochan porque carecen de la cuota de realismo social que debieran tener. Germán exige de Clara una representación pictórica de China acorde con la idea que él mismo tiene de la revolución. Si bien antes era su mejor crítico, ahora solo tiene constantes reproches sobre su obra:

-Si no comprendías lo que esto significaba, jamás debiste haber empezado a pintar. Estás aquí porque, además de ser nuestra mejor pintora, tenías una actitud valiente y rebelde. Todos lo aplaudíamos en ti, allá estaba bien, se debía atacar, abrir camino, señalar errores; pero acá eso no se justifica, la situación es otra, se ayuda a construir un mundo nuevo. Un artista en medio de esta revolución va hacia 
adelante, no puede ponerse a dudar, está entregado a una causa mucho mayor que sí mismo, nada hace a medias: "conmigo o contra mí" (Valdivieso 29-30).

Clara defiende la libertad artística y eso la lleva a recorrer las calles pekinesas en busca de su inspiración, que encuentra por ejemplo en la contemplación de antiguos objetos que para muchos recuerdan el humillante pasado feudal. Para ella, sin embargo, constituyen muestras de la refinada concepción artística y estética china. Esta actitud se pone de manifiesto en su conversación con el ceramista colombiano Tulio, quien a diferencia de ella puede habitar un dormitorio en el Instituto de Bellas Artes como becario, algo que a ella le han negado para poder atenderla "mejor". En su taller, donde él le muestra sus trabajos inspirados en técnicas ancestrales chinas, Clara se sorprende de hallar algunas pinturas abstractas:

-iPintura abstracta!

-Pintura abstracta -repitió Tulio, cogiendo la tela-; si no abría esta válvula a mi trabajo me volvía loco.

$[\ldots]$

Mientras regresaba al hotel, la frase del muchacho rebotaba contra las repetidas imágenes de la mujer y el hombre desafiantes, las banderas, el puño cerrado: "Si no abría esta válvula a mi trabajo me volvía loco". Ni positiva ni práctica resultaba, al fin de cuentas, cualquier imposición en el terreno creador (Valdivieso 211).

La contraposición entre la abstracción contemporánea y las imágenes del realismo socialista no es la única divergencia estética que tiene lugar en la novela, que revela la postura de Clara respecto de la estética de la Revolución Cultural. También ocurre cuando se alude -en distintos momentos del relato-a dos figuras del imaginario chino. La primera de ellas es el joven soldado maoísta Lei Feng, muerto en un accidente de trabajo en 1962, que ya antes de su muerte se había convertido en un modelo propagandístico del régimen. Clara se refiere a él como un anónimo, el "soldadito aquel, reverente y entregado" (Valdivieso 205), famoso por su disciplinamiento y absoluta adoración de la figura del líder, Mao Tse-Tung. Lejos de este desprecio e incluso desesperación de la pintora ante la propagación o masificación de la imagen de este héroe popular, se encuentra el personaje fantástico Sung Wu-kun, el "Rey Mono", creado por Wu Cheng-en en el siglo XVI: "nadie 
como el Rey Mono encarnó, ante el campesino oprimido por el señor feudal, ese espíritu rebelde y ágil, alegre y pícaro, necesario para enfrentar dolores y crueldades. La astucia incorporada a la moral del vasallo" (Valdivieso 207208), un sobresaliente ejemplo de individualidad y lo que ella misma subraya como "picardía", palabra con que en Chile se adorna la figura popular del "roto" chileno (pobre e ingenioso, una imagen teñida de cierto paternalismo).

\section{LOS JUECES DE CLARA}

Pero aún hay más en la tensión entre Clara y Germán. Traverso y Kottow observan en las autoras de la generación del 50 la tendencia a incorporar en sus textos figuras de autoridad que funcionan como espejos de la crítica, la censura y el rechazo que deben enfrentar en su cotidianidad: "la figura del crítico lector o juez que censura la obra. El dictamen masculino se hace presente $[\ldots]$ censurando los escritos de sus autoras, sus costumbres o su comportamiento moral, a lo cual ellas responden oscilando entre la autocensura y la deconstrucción de estos presupuestos masculinos" (23). En la novela de Valdivieso hay al menos cuatro personajes masculinos que cumplen este rol: además de Germán, el traductor que la acompaña y toma nota de lo que ella dice para transmitirlo a sus superiores y evaluar si ella se desvía de una correcta interpretación de la revolución; el subdirector de Bellas Artes, responsable en último término de la invitación a la artista, quien también interviene para vigilar y comprobar si ella está en la senda de llevar a Latinoamérica "la imagen hermana de China, porque artistas e intelectuales deben también contribuir a la tarea de representar y conectar a los pueblos" (Valdivieso 47), y finalmente, el padre, que ha sido adverso a su formación como artista y critica su forma de vida -"mezclarse con cómicos; buenos para nada" (Valdivieso 72)-, además de haber condenado claramente su viaje a la "China Roja": "quedarás marcada para siempre y podrán llamarte "comunista"" (Valdivieso 109), palabra que hasta el día de hoy es fuertemente estigmatizada en Chile por los sectores conservadores.

El esposo está ausente. De hecho, ha sido él mismo quien ha tendido un puente hacia Germán, antiguo amigo de universidad. Es él quien los presenta y quien también la empuja a hacer el viaje: "Las cartas de Germán hablaban un lenguaje nuevo, desconocido, excitante, redescubriendo el mundo. Javier, siempre ocupado de su cátedra universitaria y los diversos trabajos derivados de aquélla, encomendó más tarde a su mujer la tarea de contestarle..." 
(Valdivieso 23). Bajo la crítica ideológica y artística de Germán a Clara, hay, como se ha explicitado, otra brecha entre ambos, que es de género. Él se pone en una actitud de superioridad, refrendada por su cercanía con el partido y las autoridades chinas, que se traduce en una serie de pequeños detalles que Clara no pasa por alto, como, por ejemplo, que a él lo atiendan mejor en el hotel: "Era la insuperada diferencia de los sexos aún vigente y sostenida a pesar de proclamas y declaraciones" (Valdivieso 132-133). Una diferencia que la revolución no ha hecho sino disimular: "Expresiones, palabras y consejos para borrar miles de años de discriminación; decretos y leyes, mientras la costumbre continuaba dando órdenes a las mujeres [...] Pero ya era futuro la promulgación de leyes, futuro tal vez a largo plazo, pero futuro" (Valdivieso 133).

Por mientras, Clara no tiene otra que enfrentar el paternalismo o condescendencia con que la trata su compatriota, quien dice no comprenderla: "Realmente, no sé qué pensar de ti. ¿O se trata de aquella discusión acerca de tus dibujos? Me atreví a criticarte porque siempre lo hice, porque me preocupas" (Valdivieso 18). Esta "preocupación" justifica incluso la patologización de la artista: "Debes ir mañana mismo al médico para hablarle de tus nervios. Todo lo que dices me parece de una terrible ingratitud con esta gente" (Valdivieso 21). Clara responde asertivamente ante la doble acusación (de que es poco solidaria y también excesivamente "nerviosa"): "tal vez ambos debiéramos ir al médico y pedir un tranquilizante que nos ayude a poner las emociones en su lugar" (Valdivieso 21). La respuesta de Clara subvierte la falsa imagen de "histérica" que Germán desea instalar.

Paternalismo y patologización no terminan de cubrir la gama de conductas machistas de Germán: a pesar de su permanente actitud de condena, se trasluce también en él un interés erótico, al que ella se resiste sin palabras. En un restorán él intenta tomarle la mano, sin fortuna. Y luego, una noche, ambos cruzan miradas en el pasillo que comparten en el hotel, cuando inesperadamente, una mujer lo atraviesa fuera de sí: "pedía un hombre, expresaba desesperación, soledad y deseo" (Valdivieso 99). La reacción de ambos es contenida, tensa:

Germán permanecía estático, tenso, sujeto a una fuerza superior que detenía en sus músculos el movimiento. Bajo la bata de seda respiraba su cuerpo aceleradamente y la sangre latía en su garganta.

La alfombra, las paredes, el cielo raso parecieron girar y Clara se preguntó en un segundo: 
“¿Para qué negarse?... Todo dura un momento, la vida, la felicidad, el placer; lo único largo es el dolor. ¿Para qué negarse?...”.

A su espalda el lecho vacío estaba lleno de recuerdos. No quería recordar, no quería estar sola. Germán dio un paso y el gesto quebró la atmósfera. Ella pudo, entonces, apartar los ojos y desprenderse de su sitio. Dio un paso atrás sin volverse y frente a él cerró la puerta. (Valdivieso 100-101).

Como esta, hay otras tramas que apenas se insinúan en la novela: el pasado de Clara está marcado no solo por su "traición" a la clase y la familia de origen, sino también por un accidente posterior a la muerte de su madre, al que apenas se hace alusión: "Por una especie de autodefensa, Clara impedía a su memoria una exacta referencia sobre aquellas últimas semanas acontecidas entre la muerte de su madre y el accidente que les costara a Javier y a ella la esperanza de un hijo" (Valdivieso 71). Aunque la experiencia apenas se esboza, se suma al hilván de acontecimientos que hacen de Clara una extranjera no solo en China, sino también en el mundo social chileno, en el que la norma de género impone a las mujeres el mandato de la maternidad. Esta multiplicidad de experiencias parece explicar el epígrafe de la novela, tomado de Saint-John Perse: "Yo tenía, yo tenía ese gusto de vivir entre los hombres, y he aquí que la tierra exhala su alma de extranjera" (Valdivieso 14).

La sensibilidad de Clara ante las diferencias de género atraviesa todo el texto y se esboza tanto en sus reflexiones sobre la ancestral costumbre china de vendarles los pies a las mujeres, como en la forma en que, sutilmente, se despliega en el relato la galería de personajes masculinos que secundan a la protagonista. Germán no es el único hombre que, a su modo, acorrala a Clara. Un funcionario culto y misterioso, el subdirector de Bellas Artes encargado de su visita, insinúa también que algo pasa con ella: “¿Cómo estaba de salud? 'Hay que tener cuidado con la sequedad de la atmósfera [...] Beber mucha agua, hervida por supuesto, y alternar equitativamente trabajo y descanso"" (Valdivieso 46). En este caso, además, el diálogo se ve interrumpido (cortocircuitado) por la presencia de un traductor: "Sentía que la calidez del contacto humano se helaba a través del intérprete. Esa charla indirecta se le hacía molesta y fatigosa al cabo de un rato" (Valdivieso 49). El cansancio e impotencia que siente con Germán se convierte aquí simplemente en rabia, ofuscación, sobre todo cuando descubre que su importante interlocutor sabe inglés (ha traducido las obras completas de Shakespeare al chino) y por lo tanto podrían haber conversado sin la necesidad de un traductor: "Le parecía 
de pronto que la habían engañado, burlado, y sintió crecer en ella una rabia súbita e intensa [...] Hacía mucho tiempo que no sentía un acceso de furia semejante" (Valdivieso 53). Clara comprende que él simplemente no ha querido comunicarse con ella directamente y le ha impuesto la distancia de una traducción, bloqueando así o neutralizando lo más posible la conversación y discriminándola en diversos aspectos, con un trato ciertamente de superioridad.

Incluso el joven traductor Wang Te-en, discriminado a su vez por Clara por su origen social modesto y lo que ella interpreta como un corto alcance de miras, se pone en un plano superior cuando le da a entender a la huésped que hace reportes sobre sus conversaciones a los superiores del partido:

Y Clara enfrentó de nuevo su rostro. Su mismo rostro de siempre, un poco testarudo, un poco pálido, muy decidido. Quiso, arrebatadamente, ponerse de pie y echarlo de la habitación o acercarse y golpearle en las mejillas con la mano abierta repetidas veces, hasta que el dolor físico lo volviera a sí mismo en un grito de ira o rebeldía (Valdivieso 69).

Germán, el subdirector de Bellas Artes y el traductor reproducen, de distintos modos, una relación asimétrica de control y pretendida superioridad que para Clara no es nueva, y por eso gatilla en ella el recuerdo: conoció esto desde niña, en el hogar, a través de la figura de un padre abusivo, que engañaba a la madre y se oponía a su vocación artística: "En esos momentos la muchacha le odiaba y hubiera querido gritarlo" (Valdivieso 72).

En contraste con estas relaciones, Clara recuerda figuras positivas que la hicieron sentirse segura, valorada, contenida, como Javier, su esposo, y también su madre y su abuela: "Correr a refugiarse, como entonces, en la vieja casa de su infancia; allí donde nada podría ocurrirle y donde su madre y su abuela estarían charlando" (Valdivieso 54). La conversación entre ellas se contrapone al frío diálogo con los funcionarios chinos. Así vehiculiza imaginarios de género en los que la figura del crítico masculino (y misógino) queda en evidencia. En cuanto a Javier, que aparece a lo largo de la novela como un importante interlocutor de Clara, cumple un papel que tampoco es ajeno a otras narrativas de mujeres del periodo: el del mentor o maestro que introduce a Clara a una nueva vida cultural.

Recordó en ese momento el rostro de su marido durante aquellas largas sobremesas convertidas en lecciones. Porque Clara, hasta su matrimonio con Javier, nunca se había preocupado seriamente de 
filosofía, política o economía. Comenzó a leer, a pedir explicaciones y a escucharle. Lecciones que principiaban en Atenas y llegaban al presente a través de las escuelas idealistas y el materialismo. Educada a la moda de años anteriores, su instrucción en estas ciencias se reducía a conocimientos superficiales carentes de base lógica. Entrar, entonces, al mundo racional, colocarse en el presente después de todo un proceso lógico y concatenado, fue un aporte valioso a su labor artística. Cobró esta otra dimensión, se hizo más crítica y objetiva, aunque nadie pudo colocar jamás a su pintura algún adjetivo que señalara falta de libertad o compromiso. Clara adquiría su propia y libre concepción del mundo (Valdivieso 59).

Al leer este párrafo, es posible volver a las críticas que se hicieron en su tiempo, particularmente a la de Euler, que ve en la incomodidad manifestada por la protagonista una cuestión intuitiva, poco lógica o racional, cuando precisamente es a través de estos pasajes que se procura consolidar la imagen de una mujer que se ha formado en los problemas filosóficos, políticos y económicos de su tiempo. Clara es un personaje autónomo, que se está haciendo una idea por sí misma de la revolución, proceso que otros ponen en entredicho, además de cumplir una función muy específica en la novela, que es la del espejo autorial: así como los personajes masculinos del relato ilustran diversas relaciones de poder y autoridad en el campo cultural y familiar (el crítico, el traductor, el mecenas o patrocinante, el padre), Clara misma, en cuanto proyección autoral, ocupa un lugar en ese tramado. Pasa así a formar parte de un puzle que Jérôme Meizoz denomina "postura" autorial, algo que "no es solo una construcción comercial, ni una pura emanación del texto, ni una mera inferencia del lector" (2), sino parte de un proceso de interacción y coconstrucción retórica y sociológica, una imagen colectiva de autoría que se va elaborando discursivamente desde los textos, sus periferias (solapas, notas biográficas) e instancias epitextuales (entrevistas, reportajes, cartas, archivo) (ibid.). Para este crítico, "una persona no existe como escritor más que a través del prisma de una postura" (Meizoz 2), en una dramatización de su rol que excede a la persona "real" y que es, a su vez, una toma de posición dentro del campo cultural. En el caso de este personaje, es posible detectar las agonías que debe protagonizar una creadora en lucha por un reconocimiento intelectual, artístico e incluso social. 


\section{CONCLUSIONES}

No es menor la complejidad política de esta novela. María Montt ha escrito un excelente artículo en el que ahonda en la comprensión de este espacio de frontera o contacto con China en el contexto de la Guerra Fría y de las iniciativas del Partido Comunista Chino para dar a conocer a los simpatizantes del régimen las experiencias positivas de la Revolución, lo que se ha denominado, como explica Montt, "diplomacia cultural" (99). En su texto, Montt hace foco "en las posiciones orientalistas y esencialistas de Clara hacia los chinos" (108), que se observan sobre todo en la relación de superioridad que entabla con Wang.

Si bien es cierto que la norma de género establece una complicidad entre Wang, el subdirector de Bellas Artes y Germán con el partido, también lo es el hecho de que Clara no pueda obviar su origen burgués, que tan pronto la lleva a escandalizarse por las conductas sexualizadas de otras mujeres (como la joven Fanny ${ }^{3}$, o aquella otra, anónima, que una noche grita en el pasillo por el deseo de un hombre), como a buscar amistades que le parecen adecuadas: los españoles republicanos, pertenecientes a una élite intelectual, o la señora Brown, inglesa en quien ella puede ver un espejo de sí misma, viuda y madre adoptiva de dos niños coreanos que le han sido arrebatados por su "deslealtad" al partido. El lugar de enunciación que la escritora y Clara comparten ${ }^{4}$-que es, como se ha dicho, la procedencia de un mundo burgués, acomodado, al mismo tiempo que su adhesión a ideas progresistas que colisionan con la norma impuesta por la élite para las mujeres de su clase- acaba incidiendo en el discurso feminista de la novela, como ocurre en otros de los textos de Valdivieso y como observan la misma Montt y otras autoras como Céire Broderick, quien observa que si bien las producciones de la autora "served amistad con Germán había sido dicha entre sonrisas torcidas, pero no valía la pena detenerse en ello. La muchacha jamás entendería una amistad como la de ambos" (Valdivieso 34). A lo largo de la novela se sostiene esta relación asimétrica con Fanny, dada por la juventud, liviandad y aparente desorientación de esta última.

Lucía Guerra destaca, en un texto muy reciente, este aspecto de la novela: "Clara, es sin duda una modelización literaria de Mercedes Valdivieso, mujer que adelantándose a su época, poseía una fuerte conciencia de su autonomía y de los derechos de la mujer en el contexto más amplio de las estructuras económicas y sociales que aún hoy día producen las injusticias de la pobreza, la marginalidad y la discriminación tanto a nivel genérico como étnico" (9-10). 
to further the woman's cause in an androcentric society" (4), fracasan en lo que respecta a crear lo que Sonia Montecino denomina "sujeto múltiple" (cit. en Broderick 4), esto es, subjetividades facetadas por experiencias de clase social, edad, etnicidad, lo cual provocaría una sensación de fuerte sesgo, ya que sus personajes poseen una superioridad moral fundada en su origen privilegiado y en las certezas que defienden en cuanto sujetos occidentales.

Aun así, el ejercicio político de Valdivieso, la postura que construye a partir de esta novela es muy notable y totalmente incomprendida en su época; tanto es así que la obra fue invisibilizada en el tiempo y puesta en un lugar menor de la producción de la escritora. Una injusticia, ya que no solo aborda problemas muy propios de su narrativa, como la discriminación contra las mujeres, sino que además enuncia, con una notable conciencia literaria que la lleva a preferir una novela antes que una crónica o un testimonio, una posición política y estética absolutamente en diálogo con su tiempo, cuestionando el mandato revolucionario de un arte social y realista, para proponer una mirada contextualizada del movimiento social y una reivindicación de otras formas de vanguardia (artística). Cuando discute con Germán sobre el pueblo chino argumenta, con lucidez, que los líderes chinos se nutrieron no en Lao Tsé, Confucio o Buda, sino en Hegel, Marx o Lenin (Valdivieso 90), una crítica del colonialismo epistemológico bastante adelantada para su tiempo, como muchas otras de sus observaciones, que hacen tan necesaria la relectura de una autora que merece, sin lugar a dudas, una reinscripción en la cortocircuitada historia literaria chilena.

\section{BIBLIOGRAFÍA}

Broderick, CÉIRE. "Breaking the Silence in Mercedes Valdivieso's La brecha (1961) and Maldita yo entre las mujeres (1991)". Aigne 4, 2013, pp. 3-20.

De la Fuente, José. "La narrativa de Mercedes Valdivieso: de La Brecha a la tatamai". Literatura y Lingüística 5, 1992, pp. 39-51.

Durán Díaz, Fernando. "Conflicto en Los ojos de Bambú". La Nación, 29 de noviembre de 1964, obtenido de Memoria chilena (web), consultado el 21 de noviembre de 2021, disponible en: http://www.memoriachilena.gob.cl/602/w3-article-96087.html

Euler, Mariechen. "Mercedes Valdivieso". Escritoras chilenas. III. Novela y cuento. Patricia Rubio (ed.), Santiago de Chile, Cuarto Propio, 1999.

Guerra, Lucía. "Independencia política y artística de la mujer en Los ojos de bambú de Mercedes Valdivieso". Prólogo a Los ojos de bambú. Mercedes Valdivieso, Santiago de Chile, Ediciones Universidad Alberto Hurtado, 2021. 
Kottow, Andrea y Ana Traverso. Escribir \& Tachar. Narrativas escritas por mujeres en Chile (1920-1970). Santiago, Ediciones Overol, 2020.

Meizoz, Jérôme. "Ce que l'on fait dire au silence: posture, ethos, image d'auteur". Argumentation et Analyse du Discours 3, 2009, pp. 1-12.

Montt Strabucchi, María. "“Yo amo a China': la experiencia de una mujer en la China de los sesenta, Los ojos de bambú (1964), de Mercedes Valdivieso". Transmodernity: Journal of Peripheral Cultural Production of the Luso-Hispanic World 9, N³, 2020, pp. 97-112.

Pérez, Aina y Meri Torras. "El género de la autoría". ¿Qué es una autora? Encrucijadas entre género y autoría. Aina Pérez y Meri Torras (eds). Barcelona, Icaria, 2019, pp. 7-24.

Planté, Christine. "La excepción y lo ordinario". ¿Qué es una autora? Encrucijadas entre género y autoría. Aina Pérez y Meri Torras (eds.), Barcelona, Icaria, 2019, pp. 97-142.

Russ, Joanna. Cómo acabar con la escritura de las mujeres. Sevilla, Editorial Barrett/Dos Bigotes, 2018. Ebook.

Valdivieso, Mercedes. Los ojos de bambú. Santiago de Chile, Zig-Zag, 1964. 